\title{
Comportamiento tomográfico de la neumonía causada por SARS-CoV-2
}

\author{
Luis A. Concha-Rebollar, ${ }^{1 *}$ Eva A. Izquierdo-Echávarri, ${ }^{1}$ Luis F. Alva-López, ${ }^{1}$ Francisco J. Ayala-Ochoa ${ }^{1}$ y
} Vito S. Hernández-Melchor ${ }^{2}$

${ }^{1}$ Departamento de Imagenología, Hospital Médica Sur; ${ }^{2}$ Departamento de Fisiología, Facultad de Medicina, Universidad Nacional Autónoma de México. Ciudad de México, México

\section{Resumen}

Introducción: Desde el primer reporte de la enfermedad respiratoria causada por SARS-Cov-2 a finales de 2019, en Wuhan, China, hasta el 8 de junio de 2020, habían sido afectadas 6931000 personas en el mundo y 113619 en México, donde se carece de informes que describan el comportamiento tomográfico de esta enfermedad a lo largo de su evolución y su correlación con los datos clínicos del paciente. Objetivo: Identificar, describir y clasificar las manifestaciones en las imágenes de tomografía de tórax de pacientes con neumonía causada por SARS-CoV-2. Método: Se incluyeron pacientes hospitalizados con infección por SARS-CoV-2 confirmada mediante PCR-TR y en quienes se realizó tomografía simple de tórax. Resultados: Los patrones tomográficos más comunes fueron opacidad de vidrio despulido, consolidación, empedrado y patrón mixto, con distribución periférica, subpleural y afectación bilateral hasta en $95 \%$. Se identificaron bandas subpleurales que distorsionaban la arquitectura hasta en $62 \%$ de los pacientes, con un promedio de siete días de evolución. El aumento del eje transverso de la arteria pulmonar constituyó el hallazgo extrapulmonar más frecuente. Conclusión: Conocer el comportamiento de este tipo de neumonía permite la familiarización con los patrones tomográficos característicos, con el fin de coadyuvar a la detección y tratamiento oportunos.

PALABRAS CLAVE: Neumonía causada por coronavirus. Covid-19. SARS-CoV-2. Hallazgos por tomografía.

\section{Tomographic behavior of pneumonia caused by SARS-CoV-2}

\section{Abstract}

Background: From the first report of the respiratory disease caused by SARS-Cov-2 towards the end of 2019, in Wuhan, China, to June 8, 2020, 6,931,000 people had been affected in the world, and 113,619 in Mexico, where there is a lack of literature describing the tomographic behavior of this disease throughout its evolution and its correlation with patient clinical data. Objective: To identify, describe and classify the manifestations detected on chest computed tomography images of patients with pneumonia caused by SARS-CoV-2. Method: Hospitalized patients with RT-PCR-confirmed SARS-CoV-2 infection and who underwent a plain chest tomography were included. Results: The most common tomographic patterns were ground glass opacity, consolidation, cobblestone pattern and mixed pattern, with peripheral and subpleural distribution and bilateral involvement in up to $95 \%$. Subpleural bands that distorted the architecture were identified in up to $62 \%$ of patients, with an average of seven days of evolution. The most common extrapulmonary finding was an increase in pulmonary artery transverse axis. Conclusion: Knowing the behavior of this type of pneumonia allows becoming familiarized with the characteristic tomographic patterns, in order to aid timely detection and treatment.

KEY WORDS: Pneumonia caused by coronavirus. Covid-19. SARS-CoV-2. Tomographic findings.

Correspondencia:

*Luis A. Concha-Rebollar

E-mail: lacr03@hotmail.com
Gac Med Mex. 2020;156:396-404

Disponible en PubMed

www.gacetamedicademexico.com

0016-3813/๑ 2020 Academia Nacional de Medicina de México, A.C. Publicado por Permanyer. Este es un artículo open access bajo la licencia CC BY-NC-ND (http://creativecommons.org/licenses/by-nc-nd/4.0/). 


\section{Introducción}

A finales de 2019 se identificó el brote de una enfermedad viral desconocida en Wuhan, Hubei, China; el 11 de febrero de 2020, el Comité Internacional de Taxonomía designó al virus responsable como SARSCoV-2, conforme a la filogenia, taxonomía y práctica establecidas. Poco después, la Organización Mundial de la Salud nombró esta enfermedad como COVID-19.1 El virus se transmitió rápidamente fuera de China con una serie de casos confirmados en diferentes países. Al 9 de junio de 2020, en México se registraban 113619 casos confirmados y 13511 fallecimientos. ${ }^{2}$

La neumonía causada por SARS-CoV-2 tiene características inespecíficas y diversas en las imágenes de tomografía computarizada (TC) de tórax. Los hallazgos típicos en la TC de tórax incluyen opacidad de vidrio esmerilado, que suele ser bilateral y multifocal, consolidaciones irregulares de distribución periférica y subpleural, con predilección hacia los segmentos posteriores y lóbulos inferiores. La opacidad de vidrio esmerilado es un aumento en la atenuación que se observa en diversos procesos intersticiales y alveolares, con preservación de los márgenes bronquiales y vasculares; por su parte, la consolidación es un área de opacificación que oscurece los márgenes de los vasos y las paredes de las vías respiratorias. ${ }^{3}$

\section{Objetivo}

El objetivo de este estudio es describir las lesiones observadas en las imágenes de TC de tórax obtenidas en 112 pacientes con neumonía causada por SARS-CoV-2, quienes ingresaron al hospital Médica Sur ubicado en la Ciudad de México, correlacionar los hallazgos con el tiempo de evolución de la enfermedad y las características clínicas de los pacientes. Conocer el comportamiento de este tipo de neumonía permite familiarizar a los radiólogos y otros médicos de áreas afines con los patrones tomográficos característicos, con el fin de coadyuvar en la detección y tratamiento oportunos, así como reducir el riesgo de futuros contagios.

\section{Método}

Este estudio retrospectivo fue aprobado por el comité de ética en investigación de Médica Sur. Se seleccionaron pacientes ingresados entre el 21 de marzo y 30 de abril de 2020. Fueron incluidos pacientes hospitalizados con diagnóstico de SARSCoV-2 confirmado por PCR-TR (frotis nasofaríngeo), que se sometieron a tomografía de tórax simple; del expediente clínico electrónico se obtuvo la información de los datos clínicos. De 112 pacientes reclutados, 82 fueron hombres y 30 , mujeres.

\section{Adquisición de las imágenes}

Al ingreso de los pacientes al departamento de urgencias se realizaron estudios de tomografía simple de tórax con escáner multidetector de 128 canales. Los parámetros detallados para la adquisición de las TC fueron los siguientes: voltaje de tubo de $120 \mathrm{kV}$, corriente de tubo estándar de $159 \mathrm{mAs}$, espesor de corte de $2.0 \mathrm{~mm}$ e intervalo de reconstrucción de $1.0 \mathrm{~mm}$. El rango de exploración fue del vértice pulmonar al diafragma en plano axial. Todas las imágenes se obtuvieron con el paciente en decúbito supino e inspiración máxima.

\section{Análisis de las imágenes}

Todas las imágenes de la TC fueron almacenadas y revisadas de forma independiente por un radiólogo en turno, un radiólogo en formación y dos radiólogos adscritos al área de imagen (con amplia experiencia en imagen torácica); fueron evaluadas en estaciones de trabajo del sistema PACS, en ventana para mediastino y pulmón. Los hallazgos en la tomografía de tórax se clasificaron siguiendo el glosario de la Sociedad de Fleischner. Se tomaron en cuenta los siguientes patrones: opacidades de vidrio esmerilado, consolidación, empedrado y mixto.

Las imágenes de tomografía fueron clasificadas de acuerdo con el estadio de evolución, ${ }^{4}$ determinado conforme el número de días que el paciente refirió desde el inicio de los síntomas hasta su ingreso a urgencias. Se consideraron las radioopacidades, las cuales fueron clasificadas según su localización, afectación por lóbulo y aspecto o distribución. Se realizó una valoración de la escala de severidad y se describieron otros hallazgos asociados (adenomegalias, incremento en el diámetro transversal de la arteria pulmonar y derrame pleural).

\section{Análisis estadístico}

Los datos categóricos se muestran como porcentajes y los datos numéricos, como promedios \pm 
desviación estándar. Para evaluar si las poblaciones de hombres y mujeres provenían de una muestra con comportamiento estadístico normal se usó la prueba de D'Agostino-Pearson. Para la comparación entre hombres y mujeres se utilizó la prueba de chi cuadrada cuando se trató de datos categóricos y la prueba de $t$ de Student en los datos numéricos. Se consideraron significativos los datos con $p<0.05$, $p<0.01$ o $p<0.001$. Para evaluar la correlación entre las variables numéricas continuas se utilizó el coeficiente de correlación de Pearson. La representación gráfica de los conjuntos de Venn para describir los patrones tomográficos se realizó utilizando la página https://bioinfogp.cnb.csic.es/tools/venny/index.html. Los análisis se efectuaron con el programa Prism versión 7.0 .

\section{Resultados}

La población se distribuyó normalmente en ambos sexos de acuerdo con la prueba de D'AgostinoPearson; se identificaron 82 hombres (73.2 \%) y 30 mujeres $(26.8 \%)$. El promedio de edad fue significativamente mayor en mujeres ( $56 \pm 3.2$ años) que en hombres ( $49 \pm 1.6$ años), $p<0.05$; el rango osciló entre 19 y 85 años en los hombres y en las mujeres, entre 26 y 81 años; la mediana fue de 46 años en los hombres y de 58 años en las mujeres. Los factores de riesgo de mayor prevalencia fueron hipertensión y diabetes, sin diferencias significativas entre hombres y mujeres (Tabla 1). Todos los pacientes presentaban síntomas clínicos a su ingreso; los más frecuentes fueron fiebre, tos y disnea (Tabla 2).

\section{Características tomográficas}

En la tomografía simple de tórax realizada al ingreso de cada paciente, los patrones más comunes fueron los siguientes: opacidad de vidrio esmerilado de predominio periférico y subpleural (Figura 1), encontrado en $15.9 \%$ de los hombres y $20 \%$ de las mujeres; la consolidación, con predominio hacia los segmentos posterobasales (Figura 2); así como los patrones de empedrado y mixto, forma concomitante de los mencionados (Figura 3). En los diagramas de Venn (Figura 4) se representan los porcentajes de las diferentes combinaciones de patrones.

La afectación fue unilateral en $5 \%$ de los pacientes y bilateral en el resto, de dos o más lóbulos, con distribución subpleural y periférica de las lesiones (Tabla 3). Un hallazgo que llamó la atención fue la
Tabla 1. Factores de riesgo por sexo en pacientes con neumonía causada por SARS-CoV-2

\begin{tabular}{|l|c|c|c|c|}
\hline Factores de riesgo & Total (\%) & Hombres (\%) & Mujeres (\%) & $\chi^{2}$ \\
\hline Hipertensión & 17.9 & 15.9 & 23.3 & NS \\
\hline Diabetes & 16.1 & 14.6 & 20.0 & NS \\
\hline Cardiopatía & 4.5 & 2.4 & 10.0 & NS \\
\hline Dislipidemia & 3.6 & 2.4 & 6.7 & NS \\
\hline Neoplasia & 1.8 & 2.4 & 0.0 & NS \\
\hline Tabaquismo & 0.9 & 1.2 & 0.0 & NS \\
\hline
\end{tabular}

$\mathrm{NS}=$ no significativa

Tabla 2. Síntomas más comunes en pacientes con neumonía causada por SARS-CoV-2

\begin{tabular}{|l|c|c|c|c|}
\hline Síntomas & Total (\%) & Hombres (\%) & Mujeres (\%) & $\chi^{2}$ \\
\hline Fiebre & 83.0 & 87.8 & 70.0 & 0.03 \\
\hline Tos & 71.4 & 70.7 & 73.3 & NS \\
\hline Disnea & 67.9 & 65.9 & 73.3 & NS \\
\hline Malestar & 58.0 & 63.4 & 43.3 & 0.06 \\
\hline generalizado & & & & \\
\hline Cefalea & 47.3 & 54.9 & 26.7 & 0.01 \\
\hline Rinorrea & 25.0 & 24.4 & 26.7 & NS \\
\hline Diarrea & 16.1 & 11.0 & 30.0 & 0.02 \\
\hline Faringodinia & 14.3 & 14.6 & 13.3 & NS \\
\hline Somnolencia & 10.7 & 7.3 & 20.0 & 0.05 \\
\hline NS = no significativa. & & & & \\
\hline
\end{tabular}

NS $=$ no significativa

presencia de bandas subpleurales que distorsionaban la estructura pulmonar (Figura 5), las cuales fueron encontradas en 70 pacientes (62\%) con siete días en promedio de evolución de la enfermedad, a partir del primer día en que se presentaron los síntomas. De acuerdo con su cantidad, la presencia de bandas se evaluó como leve, moderada y severa con una escala visual y subjetiva. El hallazgo extrapulmonar asociado más frecuente (12 pacientes, $10 \%$ ) fue el aumento del eje transverso de la arteria pulmonar, medido a nivel de la bifurcación en plano transversal (tomando como referencia el tamaño de $29 \mathrm{~mm}$ ). ${ }^{5}$ Los resultados se describen en la Tabla 3.

Se clasificó a los pacientes de acuerdo con las etapas indicadas por Pan et al. (2020):4

- Etapa temprana (de cero a cuatro días después del síntoma inicial), en la que se encontraron 28 

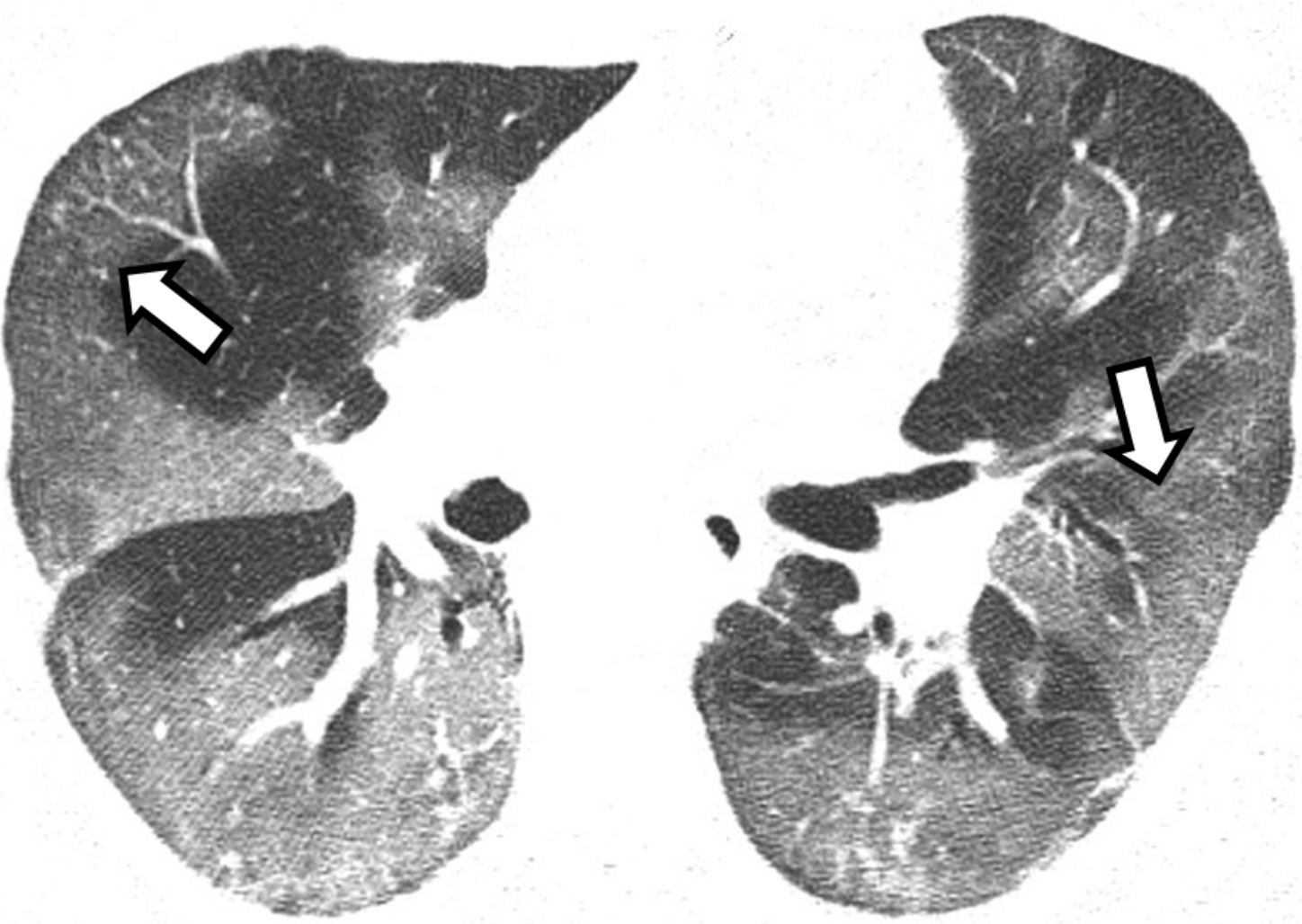

Figura 1. Hombre de 83 años con neumonía causada por SARS-CoV-2 de dos días de evolución. Se observa patrón de vidrio esmerilado de predominio periférico (flecha larga).

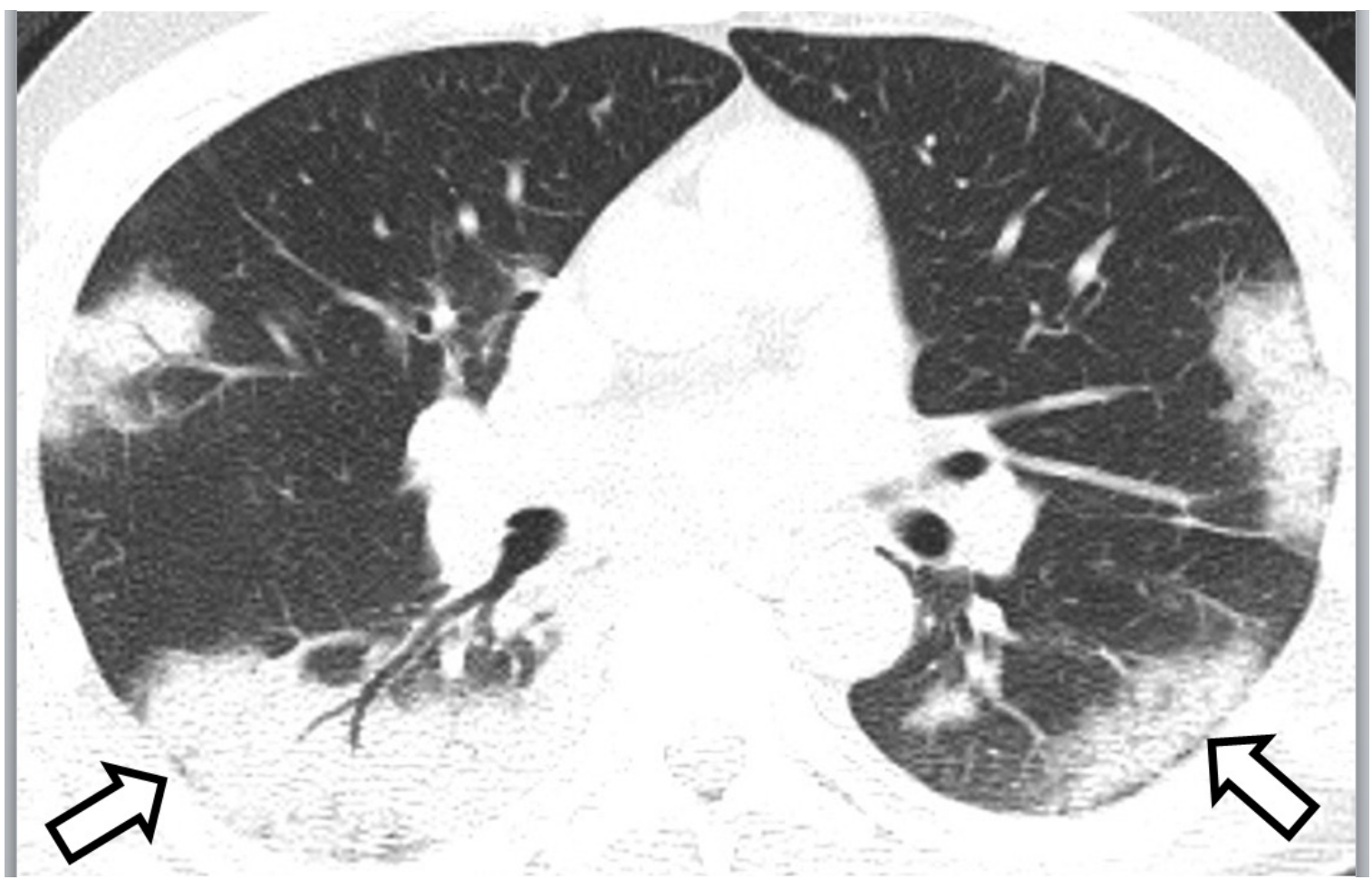

Figura 2. Hombre de 47 años con neumonía causada por SARS-CoV-2. Se observa patrón de consolidación, predominantemente en segmentos posterobasales de forma bilateral (flecha). 


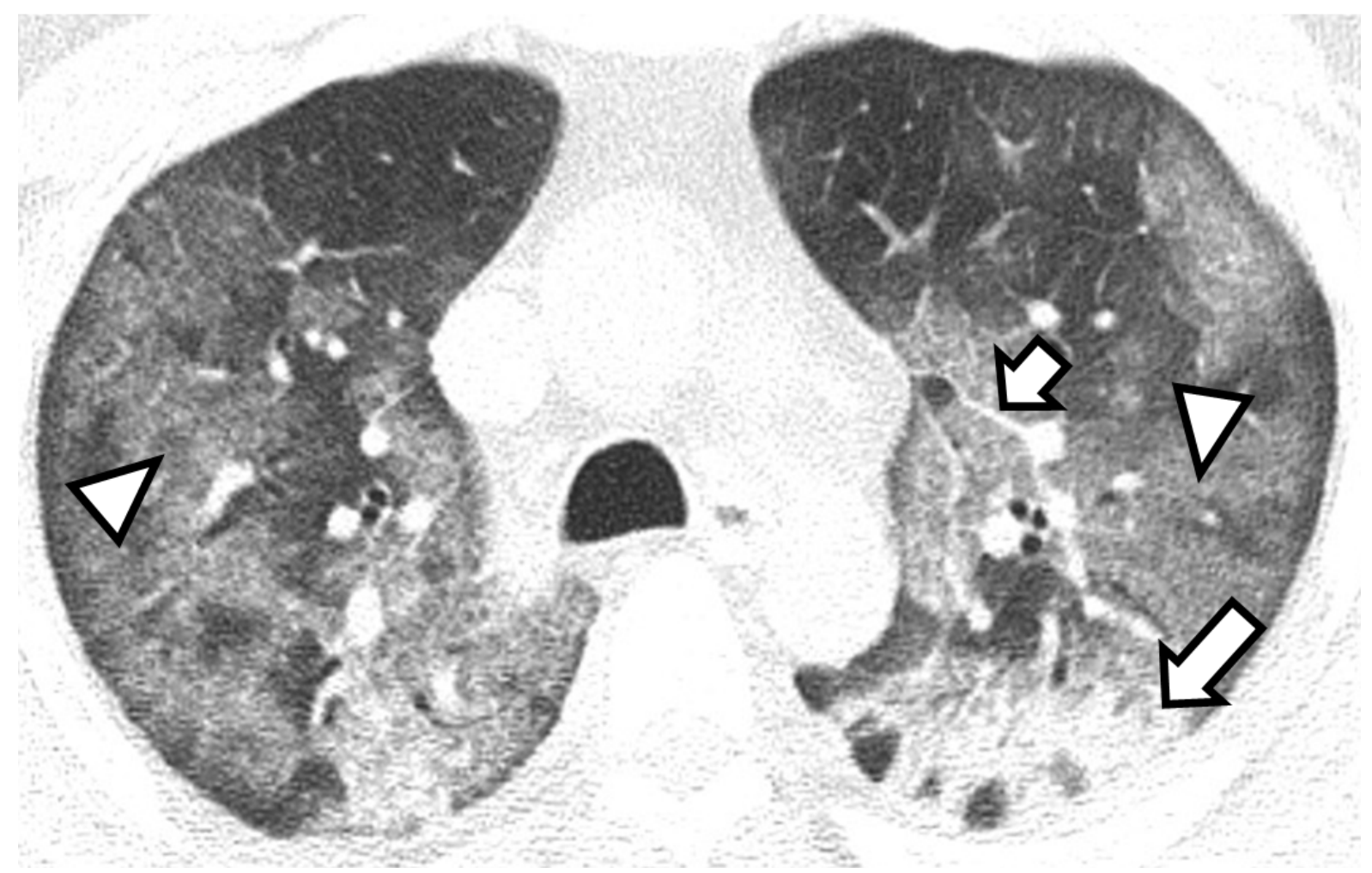

Figura 3. Hombre de 45 años con neumonía causada por SARS-CoV-2, en quien se observa patrón tomográfico mixto. Se aprecian consolidaciones densas en los segmentos posteriores (flecha larga), asociadas a discretos patrones de vidrio esmerilado (punta de flecha) y de empedrado (flecha corta).

Patrón tomográfico en hombres

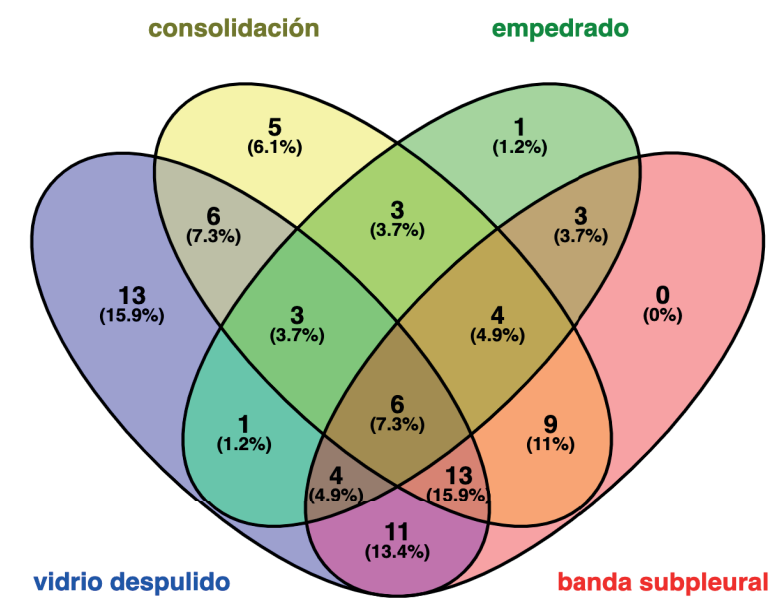

Patrón tomográfico en mujeres

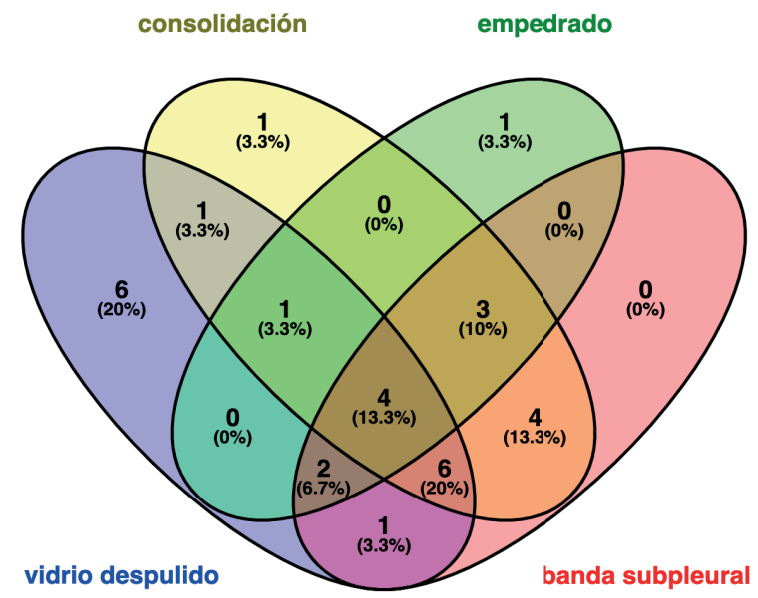

Figura 4. Diagrama de Venn. Patrón tomográfico en hombres (derecha) y mujeres (izquierda) con neumonía causada por SARS-CoV-2. En el diagrama se muestra la combinación de los patrones por sexo; el número localizado en los sectores de cada óvalo indica la cantidad de pacientes que mostraron el patrón y la concomitancia con los otros patrones.

pacientes. Se identificó patrón de vidrio esmerilado en $68 \%$ de los pacientes, de consolidación en $43 \%$ y de empedrado en $25 \%$; así como bandas subpleurales leves en $32 \%$ (Tabla 4).
- Etapa progresiva (de cinco a ocho días después del síntoma inicial), en la que se encontraron 51 pacientes. El patrón de consolidación se observó en $69 \%$, el de vidrio esmerilado en $67 \%$ y el 
Tabla 3. Frecuencia de los patrones tomográficos, su distribución, localización, afectación por lóbulos y hallazgos asociados en pacientes con neumonía causada por SARS-CoV-2

\begin{tabular}{|c|c|c|c|}
\hline Variables & $\begin{array}{l}\text { Total } \\
(\%)\end{array}$ & $\begin{array}{c}\text { Hombres } \\
(\%)\end{array}$ & $\begin{array}{c}\text { Mujeres } \\
(\%)\end{array}$ \\
\hline $\begin{array}{l}\text { Patrones } \\
\text { Vidrio esmerilado } \\
\text { Empedrado (Crazy-Paving) } \\
\text { Consolidación }\end{array}$ & $\begin{array}{l}69.6 \\
32.1 \\
61.6\end{array}$ & $\begin{array}{l}69.5 \\
30.5 \\
59.8\end{array}$ & $\begin{array}{l}70.0 \\
36.7 \\
66.7\end{array}$ \\
\hline $\begin{array}{l}\text { Bandas subpleurales } \\
\text { Leve } \\
\text { Moderado } \\
\text { Severo }\end{array}$ & $\begin{array}{c}42.0 \\
17.9 \\
2.7\end{array}$ & $\begin{array}{l}37.8 \\
19.5 \\
3.7\end{array}$ & $\begin{array}{c}53.3 \\
13.3 \\
0.0\end{array}$ \\
\hline $\begin{array}{l}\text { Distribución } \\
\text { Subpleural } \\
\text { Periférico peribronquial } \\
\text { Parches } \\
\text { Peribroncovascular central }\end{array}$ & $\begin{array}{c}68 \\
52 \\
32 \\
7\end{array}$ & $\begin{array}{c}67 \\
51 \\
32 \\
4\end{array}$ & $\begin{array}{l}70 \\
53 \\
33 \\
17\end{array}$ \\
\hline $\begin{array}{l}\text { Localización } \\
\text { Unilateral } \\
\text { Bilateral }\end{array}$ & $\begin{array}{c}5 \\
95\end{array}$ & $\begin{array}{c}6 \\
94\end{array}$ & $\begin{array}{c}3 \\
97\end{array}$ \\
\hline $\begin{array}{l}\text { Afectación por lóbulos } \\
\text { Todos } \\
\text { Inferior } \\
\text { Superior } \\
\text { Língula/medio }\end{array}$ & $\begin{array}{l}92 \\
7 \\
4 \\
3\end{array}$ & $\begin{array}{c}93 \\
7 \\
4 \\
4\end{array}$ & $\begin{array}{c}90 \\
7 \\
3 \\
0\end{array}$ \\
\hline $\begin{array}{l}\text { Hallazgos asociados } \\
\text { Aumento del diámetro transverso } \\
\text { de la arteria pulmonar } \\
\text { Atelectasias } \\
\text { Adenomegalia } \\
\text { Engrosamiento peribronquial } \\
\text { Derrame pleural }\end{array}$ & $\begin{array}{l}10 \\
3 \\
2 \\
1 \\
0\end{array}$ & $\begin{array}{l}11 \\
1 \\
1 \\
1 \\
0\end{array}$ & $\begin{array}{l}3 \\
7 \\
3 \\
0 \\
0\end{array}$ \\
\hline
\end{tabular}

patrón de empedrado en $39 \%$. Las bandas subpleurales leves se identificaron en $45 \%$ y las formas moderada y severa en 20 y $4 \%$, respectivamente.

- Etapa máxima (de nueve a 13 días después del síntoma inicial), en la que se encontraron 19 pacientes. Se observaron los patrones de vidrio esmerilado, consolidación y empedrado en 79 , 68 y $26 \%$, respectivamente. Las bandas subpleurales leves, moderadas y severas estuvieron presentes en 47,26 y $5 \%$, respectivamente.

- Etapa de resolución ( $\geq 14$ días posterior al síntoma inicial), en la que se encontraron 14 pacientes (Tabla 5). El patrón de vidrio esmerilado (71\%) se combinó con el de consolidación (64\%) y empedrado (29\%), formando patrones mixtos.

Se realizó una valoración semicuantitativa y cualitativa del patrón tomográfico para establecer una escala de severidad ${ }^{6,7}$ conforme a las sugerencias de Juárez
Hernández et al. (Instituto Nacional de Enfermedades Respiratorias, artículo en prensa, mayo de 2020). La escala de severidad pretende predecir el pronóstico del paciente dependiendo de la extensión de la afectación pulmonar por cada lóbulo y posteriormente se identifica el patrón predominante (Tabla 5). Los resultados se muestran en la Tabla 6. Los datos obtenidos con la escala fueron correlacionados con la saturación de oxígeno para determinar la reciprocidad (Figura 6).

\section{Discusión}

Las tomografías analizadas en este estudio fueron realizadas al ingreso de los pacientes; este estudio en conjunción con predictores clínicos de mortali$\mathrm{dad}^{8}$ y la saturación de oxígeno son parámetros que se usan para la toma de decisiones respecto a la intubación, hospitalización y egreso de los pacientes.

Confirmamos que el patrón de vidrio esmerilado de distribución subpleural y periférica se presentó en la mayoría de los casos y le siguió en frecuencia el patrón de consolidación, los cuales en pocas ocasiones se presentaron de forma aislada, tal como se muestra en la Figura 4 (diagrama de Venn); el patrón mixto (combinación de dos o más patrones) fue el tercero en frecuencia. En numerosos pacientes se observaron bandas subpleurales, las cuales, de acuerdo con la revisión bibliográfica, podrían sugerir bandas fibrosas en formación, que aparecen después de la fase aguda de la enfermedad. ${ }^{9}$ Sabemos que la fibrosis pulmonar puede ser una secuela del síndrome de dificultad respiratoria aguda y aunque el virus sea erradicado en pacientes recuperados de COVID-19, el desarrollo de fibrosis pulmonar es irreversible, por lo que se sigue especulando acerca de las consecuencias pulmonares a largo plazo de COVID-19 y no deben asumirse sin un estudio prospectivo adecuado. ${ }^{10}$ En cuanto a la distribución de las lesiones, confirmamos la afectación pulmonar bilateral y multifocal, lo que coincide con los resultados de investigaciones previas.

En relación con las etapas de la enfermedad mencionamos lo siguiente:

- Etapa temprana: se ha observado el patrón de vidrio esmerilado como hallazgo principal, con distribución subpleural en lóbulos inferiores, uni o bilateralmente. En nuestro estudio, la presentación coincidió, sin embargo, identificamos también patrones de consolidación y empedrado, así como incipientes bandas subpleurales. En esta 


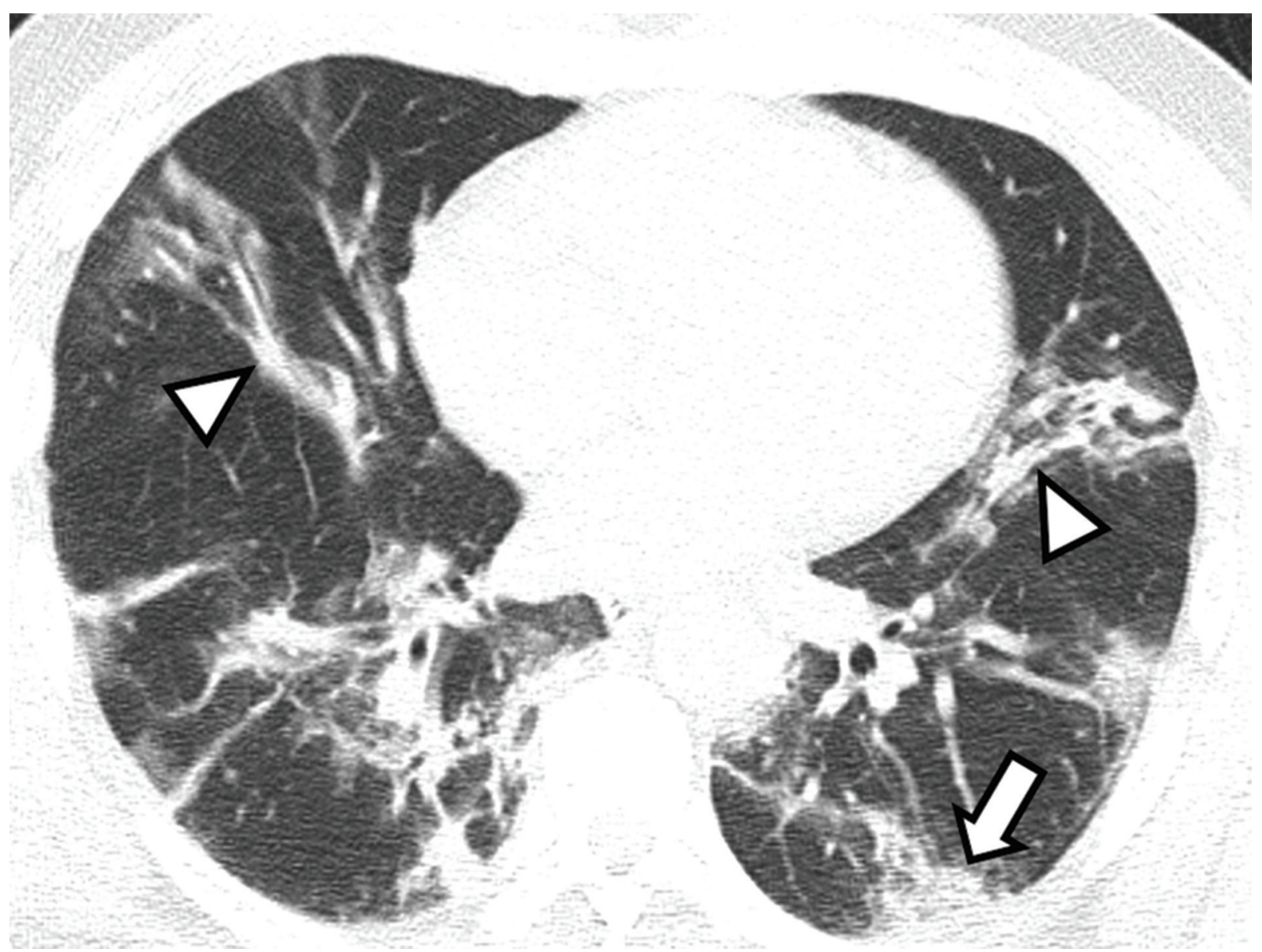

Figura 5. Hombre con neumonía causada por SARS-CoV-2 de 10 días de evolución, quien se encuentra en una etapa máxima de la enfermedad. Se observan bandas subpleurales (cabeza de flecha) asociadas a consolidaciones densas (flecha).

Tabla 4. Características clínicas y tomográficas por etapas de la enfermedad en pacientes con neumonía causada por SARS-CoV-2

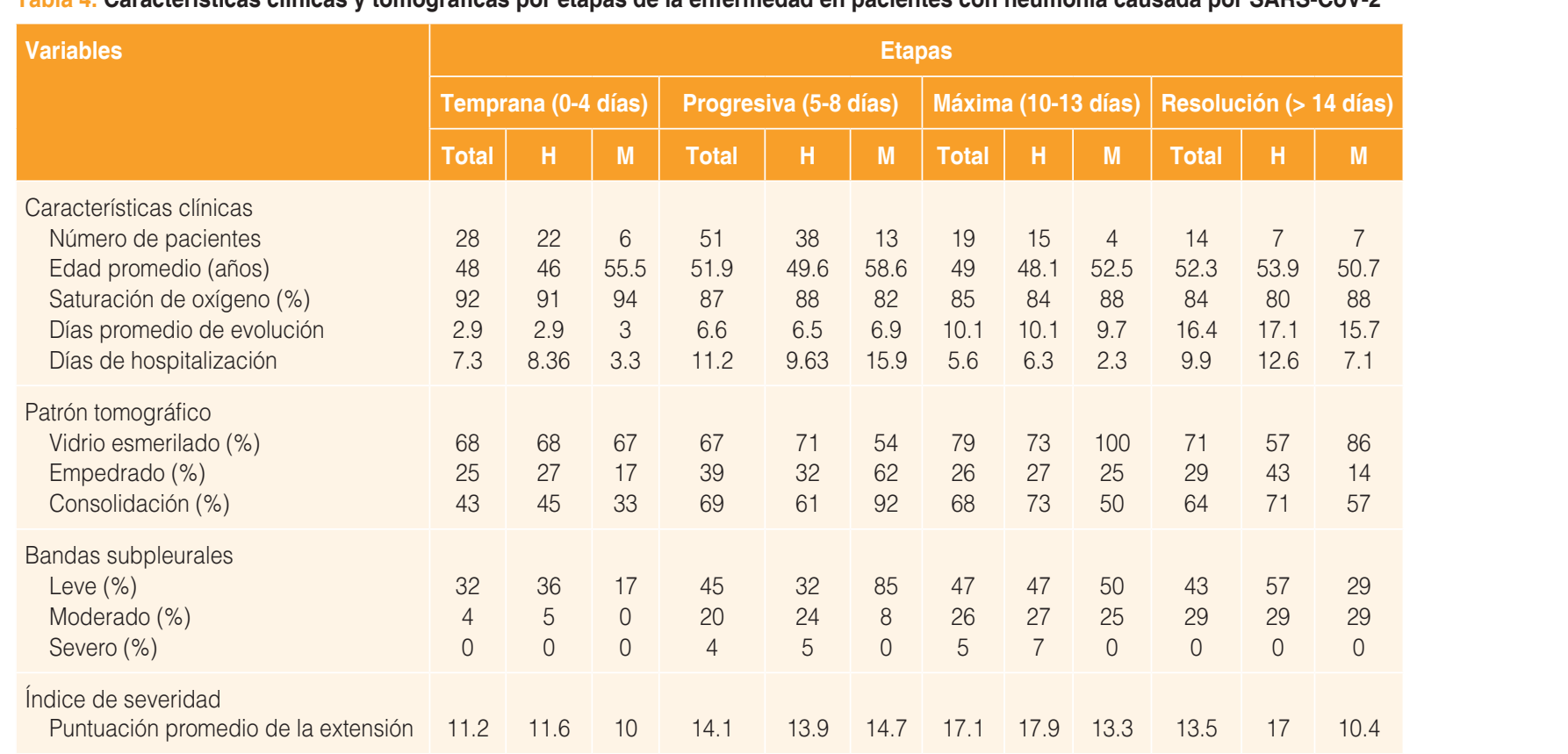


Tabla 5. Valoración semicuantitativa y cualitativa de la extensión de las lesiones por lóbulos pulmonares en pacientes con neumonía causada por SARS-CoV-2

\begin{tabular}{|l|c|l|}
\hline \multicolumn{3}{|c|}{ Valoración semicuantitativa } \\
\hline Puntuación & $\begin{array}{c}\text { Porcentaje de } \\
\text { afectación }\end{array}$ & Interpretación \\
\hline 1 & $\leq 5$ & Afectación leve: 1 a 5 puntos \\
\hline 2 & $>5-25$ & \\
\hline 3 & $>25-50$ & $\begin{array}{l}\text { Afectación moderada: }>5 \text { a } \\
15 \text { puntos }\end{array}$ \\
\hline 4 & $>50-75$ & Afectación severa: $>15$ \\
\hline 5 & $>75$ & puntos (máximo 25 puntos) \\
\hline Categoría & $\begin{array}{l}\text { Patrón } \\
\text { predominante }\end{array}$ & Fases de la enfermedad \\
\hline A & Vidrio esmerilado & Inicial \\
\hline B & Empedrado & Progresión de la enfermedad \\
\hline C & Consolidación & Enfermedad avanzada \\
\hline
\end{tabular}

Escala de severidad sugerida por Juárez Hernández et al. (Instituto Nacional de Enfermedades Respiratorias, artículo en prensa, 2020).

Valoración semicuantitativa: se asignan puntos a cada lóbulo (cinco lóbulos, tres derechos y dos izquierdos) de acuerdo con el porcentaje de la extensión de la afectación, posteriormente se suman los puntos y se interpretan de acuerdo con la columna de la derecha.

Valoración cualitativa: se asigna una letra de acuerdo con el patrón tomográfico predominante, y se interpreta de acuerdo con la columna de la derecha.

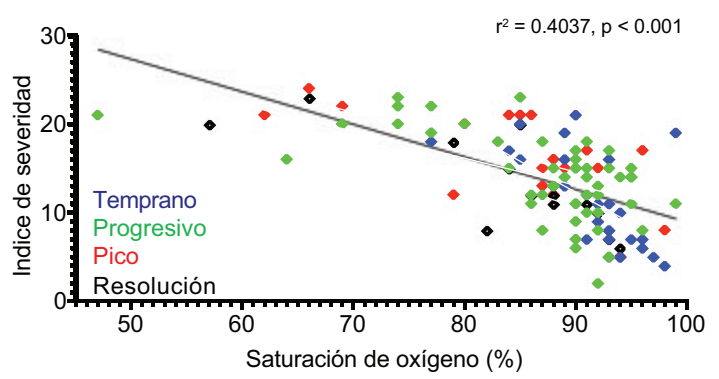

Figura 6. Correlación del índice de severidad versus saturación de oxígeno de acuerdo con la etapa. Existe una relación entre el índice de severidad (por tomografía) y la saturación de oxígeno $\left(r^{2}=0.4037\right.$, $p<0.001)$; sin embargo, en el análisis individual se observó que en etapas tempranas (azul) la mayoría de los pacientes presentó saturación de oxígeno > $85 \%$, aun cuando algunos presentaban un índice de severidad alto. En otras etapas se observaron más pacientes con saturación de oxígeno $<80 \%$ y en todos ellos el índice de severidad fue severo (> 15 puntos). Una saturación de oxígeno alta no excluye la posibilidad daño pulmonar extenso.

etapa, los diferentes patrones se pueden presentar de forma independiente, no así en las posteriores.
- Etapa progresiva: de acuerdo con la literatura es común encontrar los patrones de vidrio esmerilado de forma difusa, de empedrado y de consolidación de forma bilateral. En nuestro estudio predominó el patrón de consolidación, seguido por el de vidrio esmerilado y, por último, de empedrado. A partir de esta etapa, los pacientes muestran patrones mixtos y difícilmente se observan patrones únicos.

- Etapa máxima: el hallazgo más frecuente fue la consolidación densa. En nuestra investigación, los hallazgos incluyeron patrones de vidrio esmerilado, consolidación y empedrado, así como bandas parenquimatosas que causan distorsión de la arquitectura (Figura 5).

- Etapa de resolución: es común encontrar extenso patrón de vidrio esmerilado como lesión residual de las consolidaciones. En nuestro estudio se encontraron patrones mixtos, con bandas subpleurales como lesiones residuales de la etapa aguda.

Los hallazgos son consistentes con los reportados por Lomoro et al.,11 quienes hicieron una revisión bibliográfica de 26 artículos, 3886 pacientes (2059 hombres y 1827 mujeres), con una edad media de 49.39 años. Los siguientes hallazgos se indican en orden de frecuencia: patrones de vidrio esmerilado, consolidación y mixto; y distribuciones bilateral, periférica, subpleural y en los lóbulos inferiores, lo que coincide con los observados durante nuestra investigación.

El hallazgo extrapulmonar más frecuente fue el diámetro transverso del tronco de la arteria pulmonar $>29 \mathrm{~mm}$, el cual se considera el signo tomográfico más específico para diagnosticar hipertensión pulmonar por tomografía y aunque un valor inferior no excluye necesariamente esta patología, tiene un alto valor predictivo positivo de $97 \%$, una sensibilidad de $87 \%$ y una especificidad de $89 \%$ para sugerir esta patología. ${ }^{5}$ Este hallazgo no se menciona en otras revisiones, quizá por su carácter subjetivo, sin embargo, su etiología podría estar en relación con los procesos trombóticos en la patogenia de COVID-19.12

Respecto a la escala de severidad sugerida, es útil únicamente para orientar acerca del grado de afectación del parénquima pulmonar, pues no se encuentra en relación directa con la saturación de oxígeno ni con el cuadro clínico real del paciente, con lo que se comprueba la disociación clínico-radiológica referida en la literatura ${ }^{13}$ (Figura 6). 


\section{Conclusión}

Proporcionamos la primera descripción de los patrones tomográficos típicos de la neumonía causada por SARS-CoV-2 en pacientes mexicanos y analizamos la frecuencia con la que se presentan en hombres y mujeres en las diferentes etapas de la enfermedad. Lo anterior permitirá la familiarización de los médicos con los hallazgos tomográficos clásicos para realizar una detección temprana. En nuestra población, el diámetro aumentado de la arteria pulmonar fue un hallazgo común que puede indicar hipertensión pulmonar. Demostramos que las bandas subpleurales aparecen después de la fase aguda de la enfermedad, pero se requiere un estudio prospectivo a largo plazo para corroborar si pueden causar fibrosis pulmonar. Asimismo, se comprobó que la escala de severidad pulmonar sugerida por Juárez Hernández et al. no siempre se correlaciona con el estado clínico del paciente y es útil únicamente para proporcionar una idea de la extensión del compromiso pulmonar y con ello decidir el manejo del paciente.

\section{Conflicto de intereses}

Los autores de esta revisión declaran que no tienen ningún conflicto de intereses.

\section{Financiamiento}

No se recibió financiamiento para escribir este artículo.

\section{Responsabilidades éticas}

Protección de personas y animales. Los autores declaran que para esta investigación no se realizaron experimentos en seres humanos ni en animales.
Confidencialidad de los datos. Los autores declaran que han seguido los protocolos de su centro de trabajo en cuanto a la publicación de datos de pacientes.

Derecho a la privacidad y consentimiento informado. Los autores han obtenido el consentimiento informado de los pacientes y/o sujetos referidos en el artículo. Este documento obra en poder del autor de correspondencia.

\section{Bibliografía}

1. Hosseiny M, Kooraki S, Gholamrezanezhad A, Reddy S, Myers L. Radiology perspective of coronavirus disease 2019 (COVID-19): lessons from severe acute respiratory syndrome and Middle East respiratory syndrome. AJR Am Roentgenol. 2020;214:1078-1082.

2. World Health Organization [Internet]. Suiza: Coronavirus disease (COVID-19) weekly epidemiological update and weekly operational update; 2020.

3. Zu ZY, Jiang MD, Xu PP, Chen W, Ni QQ, Lu GM, et al. Coronavirus disease 2019 (COVID-19): a perspective from China. Radiology. 2020;296:E15-E25.

4. Pan F, Ye T, Ye T, Sun P, Gui S, Liang B, et al. Time course of lung changes at chest CT during recovery from coronavirus disease 2019 (COVID-19). Radiology. 2020;295:715-721.

5. Peña E, Dennie C, Veinot J, Hernández-Muñiz SH. Pulmonary hypertension: how the radiologist can help. Radiographics. 2012;32:9-32.

6. Wang Y, Dong C, Hu Y, Li C, Ren Q, Zhang X, et al. Temporal changes of CT findings in 90 patients with COVID-19 pneumonia: a longitudinal study. Radiology. 2020 Aug;296(2):E55-E64.

7. Yuan M, Yin W, Tao Z, Tan W, Hu Y. Association of radiologic findings with mortality of patients infected with 2019 novel coronavirus in Wuhan, China. PLoS One. 2020;15:e0230548.

8. Ruan $Q$, Yang K, Wang W, Jiang L, Song J. Clinical predictors of mortality due to COVID-19 based on an analysis of data of 150 patients from Wuhan, China. Intensive Care Med. 2020;46:846-848.

9. Smithuis F, Smithuis R. 32 cases of suspected COVID-19. Imaging findings and follow up [En línea]. Países Bajos: Radiology Assistant; 2020.

10. Spagnolo P, Balestro E, Aliberti S, Cocconcelli E, Biondini D, Casa G, et al. Pulmonary fibrosis secondary to COVID-19: a call to arms? Lancet Respir Med. 2020;8:750-752.

11. Lomoro P, Verde F, Zerboni F, Simonetti I, Borghi C, Fachinetti C, et al. COVID-19 pneumonia manifestations at the admission on chest ultrasound, radiographs, and CT: single-center study and comprehensive radiologic literature review. Eur J Radiol Open. 2020;7:100231.

12. Bikdeli B, Madhavan MV, Jiménez D, Chuich T, Dreyfus I, Driggin E, et al. COVID-19 and thrombotic or thromboembolic disease: implications for prevention, antithrombotic therapy, and follow-up. J Am Coll Cardiol. 2020.

13. Inui S, Fujikawa A, Jitsu M, Kunishima N, Watanabe S, Suzuki Y, et al. Chest CT findings in cases from the cruise ship "Diamond Princess" with coronavirus disease 2019 (COVID-19). Radiology: Cardiothoracic Imaging. 2020;2:e200110. 